\title{
The online potential of art creation and dissemination: DeviantArt as the next art venue
}

\author{
Almila Akdag Salah \\ Virtual Knowledge Studio/KNAW \\ Cruquiusweg 31, 1019AT, Amsterdam, Netherlands \\ almila.akdagsalah@vks.knaw.nl
}

\begin{abstract}
DeviantArt is an online community dedicated to sharing user-generated artworks. Launched in 2000, today this initiative has about 11 million members coming from over 190 countries. The website offers various web-based services to its members enabling and enforcing a strong social interaction. With its collection of around 100 million works, DeviantArt (DA) is the biggest art market of the world, presenting a new mode of displaying, evaluating and consuming arts. In that sense, DA generated a platform free of institutional and governmental politics, democratising the way arts are generated, shared and enjoyed. This paper discusses the collaborative aspects of this autonomous venue, and questions the potential of this initiative in becoming the new art venue of the 21st Century.
\end{abstract}

DeviantArt. Online communities. Art market. Social network analysis. Collaborative art making.

\section{INTRODUCTION}

When in 1863 the famous exhibition space of French Academy Salon refused about 4,000 out of 5,000 submissions, the artists voiced their concerns about the relevance of academic criteria; whereupon Napoleon started Salon des Refuses to let the public judge the quality of the rejected artworks (Harrison, 1988, p. 506). Today DeviantArt (DA), an online community of artists and art appreciators, plays the role of the Salon des Refuses by displaying its members' artworks for everyone to see, evaluate and buy. The voice of the public, in this case, consists of at least 12 million members of DeviantArt (DA) from over 190 countries.

In 2008, DA is visited by 32 million users, and it is listed among the top ten visited websites in the category of arts. As a commercial enterprise, DA is surely a successful endeavour, even though it does not reach hundreds of millions Internet users like other online Social Network Sites (oSNS) such as Facebook or MySpace, which are the latest phenomena in online interaction and Internet usage (Boyd, 2007a; Lewis et. al. 2008; Mayer et. al. 2008; Thelwall, 2009).

In a recent study, oSNS are defined as web-based services for users to construct a public or private profile and to connect with other users in a bounded system (Boyd, 2007b). In this sense, DA resembles SNS as it offers basic services to its users, and it creates a community structure. However, DA works like a blog-sphere as well (see Adar et al. 2004 on blogging), as each DA member is given a website on his/her own. The combination of both services, its focus on user-generated art, and its success make DA a unique enterprise, challenging and questioning the art market on many relevant points. So far, an in-depth study of DA from an art historical point of view has been missing. This paper aims to fill this gap by contextualising this SNS within the framework of art historical domain.

Since its first launch in 2000, the DA community developed a structure that is astonishingly similar to the existing art market. Subsequently, DA presents a case study that is immensely rich in providing data for observation of how certain roles such as curators or art critics come into being, especially as these roles were not designated by the website owners themselves, but emerged on their own throughout the years. On the other hand, DA's organisation furthers a democratisation of arts that has never been seen before: DA members are the creators (i.e. the artist), the visitors (i.e. the audience), the writers of news, critiques etc. (i.e. the art critic), the sellers (i.e. the gallery owner), and organisers of events (i.e. the curator) of DA's 
art collection. What is more, roles that, in the traditional art world, are reserved for those with advanced degrees in art history are now accessible to members who have no prior knowledge or education in arts. As such, the site would seem to be the ideal antidote of the current westernoriented art world, and provokes by its sheer existence many key questions discussed by art historians (Preziosi, 1991, 2003, 2006, 2009). It is the aim of this paper to position DA within these debates, and relate the organisation and dynamics of DA to the assumptions of the art historical cannon, thereby questioning the fundamental basis of the discipline and the power structure of the art market.

The key objectives of this paper are addressed in separate sections. First I will discuss the identity of the artist in the context of this new venue. Next, I will elaborate on the importance of institutions in the evaluation and maintenance of arts. Finally, I will highlight collaborative attempts at curating and creating arts in DA against a backdrop of art historical setting.

\section{THE IDENTITY OF THE ARTIST}

The concept of identity is used in many different contexts and covers a deal. A general description that is utilised in social sciences refers to the term as 'an individual's comprehension of him or herself as a discrete, separate entity'. More importantly, when the term is expanded to represent not an individual, but a minority group, it takes on a political role. Through these politics, and the onset of postcolonial critique, minority groups claimed their rights in all aspects of society. In the early 80 's, such identity politics began to have repercussions in the art world as well, in the form of a scathing critique of the art canon that was said to prioritise a 'White, Anglo-Saxon, Male' point of view (i.e. see Gouma-Peterson \& Mathews; 1987 and Wanda, 1988).

Today, identity politics may be claimed to have served their purpose by creating a place for artists belonging to minority groups. However, in the global art market, such a 'placement' can easily become a 'labelling' that spawns new problems. Belonging to such a minority group can easily force the artist into a local or ethnic form, as opposed to the white Anglo-Saxon male who retains all freedom by being the norm.

Take for instance biennials, which offer nice opportunities for local artists to be introduced to an international audience. However, earning such an international acknowledgment comes with a prize, especially for the non-Western (otherised) artists: more often than not, they find themselves labelled first and foremost by their nationality or ethnicity (Carlos, 2002; Becker \& Okwui, 1998). In comparison, DA offers an alternative environment for displaying one's artworks, where to share the information of one's nationality or ethnicity is an open decision. Members could choose to fill-in the demographic data to flag their background, or skip this step, or even create a false identity.

Another (maybe more to the core) face of identity in the context of the art-world is the artistic identity itself. Before discussing how much the nationalistic or ethnical background of the artist is projected into the creation process of an artwork, we must discern what it makes this process 'artistic' in contrast to others: what makes the artist an artist? This question becomes especially relevant in the realm of DA that is outside the traditional mechanism of art world. Today, the identity of an artist is bestowed by the education system, or in rare cases, by certain institutions of the art world.

DA deviates in this regard from the norm, as in the context of DA, the line that separates the amateur and the professional is irrelevant. In order to become a DA member one does not need to have a background or education in arts. Moreover, the users can take on more than one identity; it is easy to traverse from one role to the other (i.e. one can both act as an artist and a curator), and/or combine them all in one member profile. Some members choose to have more than one profile, and display their works belonging to different genres through different user names.

We can ask ourselves what kind of freedom is gained by employing a digital medium, which makes numerous tools and the means for creating artificial identities available to its users. DA works like a blog-software, presenting each member with an individual website, where the member can upload his/her own works, create collections from other members' works, write (blog-like) 'journals' or prepare 'news', and generate events or competitions. DA has only some basic rules about copyright infringement and about nudity issues.

The simplicity of reaching millions does not necessarily mean that it is easy to become successful among the DA community. On the contrary, DA has a delicate power structure based on simple statistics that reflects the popularity of each member. These statistics are generated by counting of how many times a DA member's page is visited (i.e. number of pageviews), as well as how many comments she has received. The ubiquitous power law that governs the free-scale networks (Adamic et al. 2001) can be observed here as well: The more popular you are, the higher the chances of receiving new visitors to your DA page, which in return makes you more and more 
popular. The end result is that a few members enjoy an enormous number of pageviews, and achieve the luxury of reaching the masses easily and quickly.

The rules of the game in DA are quite different than the art market. For example, Benneth Klein (2008), a creative director, explains that after realising his original artworks do not attract much pageviews, he studied the most 'popular' works in DA, and created a series in anime style. This series, what he calls 'Gundam Girls, exploiting the contrast between bikini babes and Gundam Mecha gear - strong and vulnerable, organic and mechanical, masculine and feminine', became a hit, and his pageview statistics increased from around 10 visitors to hundreds a day. Of course his success depends on him continuing to produce with this style. When he applied the same idea (robot + human hybrid forms) with attractive looking male bodies, he witnessed a drop in his audience.

Klein's example illustrates the hidden limitations of DA in the face of the seeming freedom it bestows to its members. Just like the traditional art market, conforming to the rules of the game is a necessary (but not sufficient) condition of becoming successful, yet the rules in DA are different. One can join DA in an amateur spirit and turn professional overnight. One can try out different identities, like changing clothes, and find out which one is designated to become successful. While this is certainly a much greater opportunity then what the traditional art market offers, it also implies that the artist can change much to conform to the structure of the medium. It is thus imperative to study not only the dynamics of how to become successful in DeviantArt, but also how members cross the identity boundaries from being an amateur to professional, or from being an artist to a curator or an art critic.

\section{THE ROLE OF INSTITUTIONS}

Art evaluation mechanisms, such as museums, biennials, galleries, curators, connoisseurs, and art dealers, establish a value system, which determines the value of an art work, or more fundamentally, which designates a work as a work of art. This happens by attributing a monetary value to the work, or by promotion of the work through legitimate channels (art magazines, shows, fairs, biennials, exhibitions, auctions, catalogues). DA has created its own evaluation mechanisms, almost spontaneously or autonomously, where the power of the networked society is employed to the fullest extent, and the user actions (like tagging a work as a favourite, adding comments to a piece, etc.) play a role in establishing the value of the work. At a first glance, this effectively removes the need for expertise, and distributes the judgment over the community. However, as in the case of the freedom DA bestows to its members for creating any type of identity, the network structure that appears to distribute the value judgement over the community might be concealing another power structure. Only a thorough evaluation of DA through network analysis techniques would let us see the real power distribution of the community.

Here, one of the most challenging points is the realisation of DA's social dynamics that reflect the mechanisms of evaluation. This will in turn reveal whether DA harbours a similar authoritative structure to cultivate experts and whether it has spontaneously evolved a legitimisation system to evaluate artworks or not.

How did traditional art evaluation venues adapt to the digitally connected society? Without doubt, museums were among the main venues of the 'gate-keeper' system that distinguished between high and low art (Varnedoe, 1990; Karp, 1991). Since the introduction of Internet, museums (and libraries) have shown great interest in applying the technological expansion and ease offered by the World Wide Web. Yearly conferences on Museum \& Web have started as early as 1996, and many projects are reported with the aim of building an online community for museums (Russo \& Watkins, 2008; Adams et. al. 2001). The most thriving examples among these are the ones that rely on already established communities. For example, at Brooklyn Museum, Caruth \& Bernstein have been developing projects that run in various online social networks such as Twitter, Facebook, MySpace etc., in order to test various options to build an online community of/for the museum (2007). The measure of success is the attention the online museum receives, and this is quantifiable.

Agencies like compete.com or Alexa are wellknown and trusted sources that measure and publish statistics of web traffic, enabling quantification of the popularity of a website. Figure 1 shows the ranking of DeviantArt in comparison to the four art museums that were among the top five most visited museums in 2007 . The figure reflects clearly the overwhelming popularity of DAs website in relation to museums' websites. To clarify the numbers shown in the figure, ranking is measured through the web traffic each web page has attracted over a given period. A ranking of 277 means that over the course of one year, DA was the $277^{\text {th }}$ among the most visited websites. Metropolitan Museum of Art was $4.850^{\text {th }}$, followed by MOMA (NY), Tate Modern, and Louvre. 


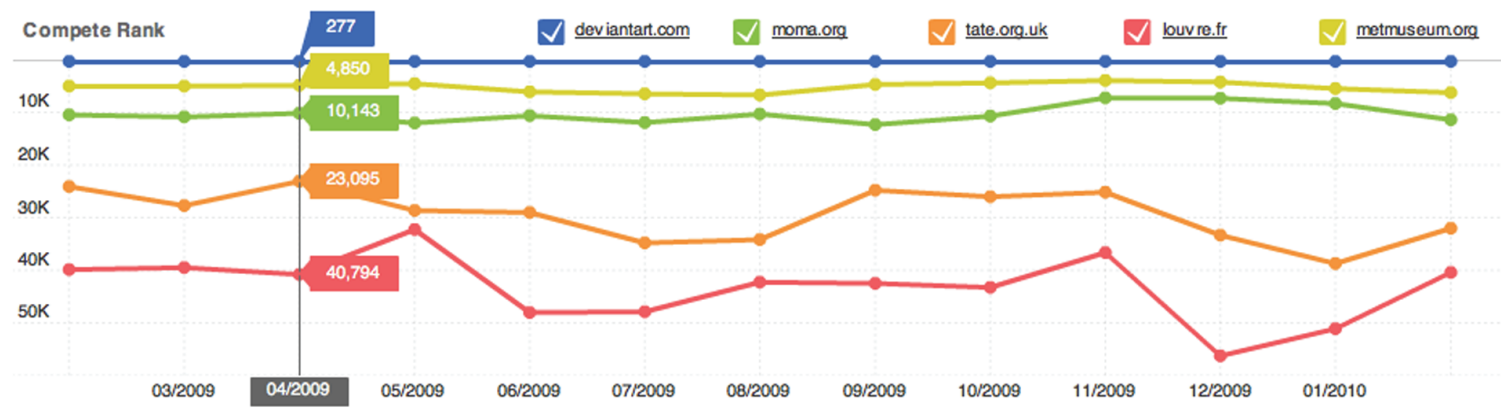

Figure 1: Ranking of DeviantArt, MOMA, Tate Modern, Louvre \& Metropolitan Art Museum (2009-2010). The data are retrieved from the web-traffic agency compete.com on 01.04.2010

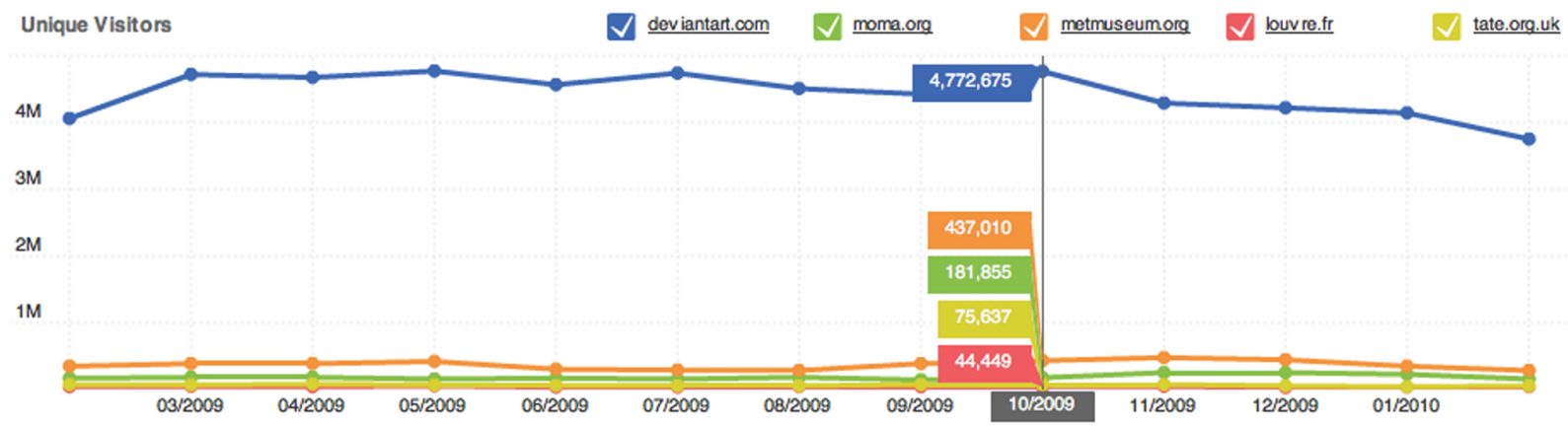

Figure 2: Unique visitor numbers of DeviantArt, MOMA, Tate Modern, Louvre \& Metropolitan Art Museum (2009-2010). The data are retrieved from the web-traffic agency compete.com on 01.04.2010

If we look at the numbers of physical visits to these museums, with a total number of $8,300,000$ people, Louvre was the first, followed by Tate Modern, British Museum and Metropolitan Museum of Art (5.191.840, 4.837.878 and 4.547.353 respectively) (Morris et. al. 2008). Figure 2 shows the number of unique visitors each webpage has received in 2009. Like ranking, the term 'unique visitor' is used to measure the popularity of a website, and is calculated by counting each person once, no matter how many times they visit a site in a given month. As we have mentioned, DA had 32 million unique visitors in 2009, which is a number much greater than the reach of any museums' physical or virtual visitor count.

One question we need to ask at this point relates to the commercial aspect of such numbers, as DA is primarily a commercial website. Market forces and politics play a role on the creation of arts, whether they are funded through states, museums, foundations, or promoted through individual channels.

At first look, commercial enterprises such as DeviantArt evoke a higher sense of involvement with the art market and value systems compared to regular art institutions like museums. The political nature of museums and gallery spaces has been a topic of discussion since the publication of Inside the White Space, if not before (O'Doherty, 1999). In contrast to these institutions, DA presents a platform where the regulation and evaluation happens through the opinion of the majority, which is in a sense liberating with a bonus of effacing the distinction of high and low art.

\section{COLLABORATIVE ART MAKING}

The British artist Roy Ascott was one of the pioneers in promoting the creation of art rather than the artworks themselves, and as such, he can be rightly christened as the forefather of what we call collaborative art today. Already in 1961, Ascott was teaching at Ealing School of Art a curriculum that made use of cybernetics (control theory), i.e. defining art as a process, and stressing the importance of user participation in this process. In 1964, he displayed pieces based on these ideas in an exhibition entitled Diagram Boxes and Analogue Structures. Later on, he published the philosophical aspects of his work in the journal Cybernetica in a 
two-part article, 'Behaviorist Art and the Cybernetic Vision' (Ascott, 1966, 1968). In this paper, Ascott describes a cybernetically driven art theory called Cybernetic Art Matrix (CAM).

The environment of CAM is set up in a way to force the audience, or in Ascott's terminology, the participant, to give feedback, through which the participant engages in a decision making activity concerning the art object. The end result is the joint creation of the object by the artist and the participant. Ideally, this object would be an open project, in constant flow and never ceasing to take on new aspects. With every new participant, the creation process would re-start or expand, and this circulation would continue until some physical limit (e.g. end of the exhibition) brings the process to a halt. Today, this theory sounds obsolete, yet if we look at the common aspects of New Media artworks we can still discern some of Ascott's ideas, which back in the 1960s were quite novel. At that time, Ascott's ideas were obviously impossible to implement. Telepresence only became possible after Internet connected millions of users.

Apter notes that Ascott's idea of 'art as a process' had a great appeal for artists, as it formulated art as a dynamic system that comes into existence only through the feedback loop between the artist and the audience. As Ascott details in his papers, this line of thinking is in continuity with the modern art's 'behaviorist' tendencies (Ascott, 1966). In contrast to the traditional understanding of an art object with a well-defined body, ways of construction (such as painting and sculpture), and a specific space for dissemination (i.e. museums, galleries, fairs), cybernetic art opened the doors to a new way of making, experiencing, sharing and displaying art.

Today, the idea of mobilising user-generated content and converting 'free labour' into an act of creating knowledge as well as art has been already put into use in various projects. The most prominent project in these type endeavours is probably the Flickr Commons, which started with the collaboration of Flickr community with the Library of Congress. The library made a portion of its huge photograph collection available for Flickr users to tag and annotate (Oates 2008). Today, many other organisations are subscribed to the project, and the community actively attaches keywords to the ever-growing collection, rendering it easier to reach through keyword searches.

Another project that commenced with the initiative of Wikipedia under the flag 'Wikipedia loves Art' spread from USA to Britain and Netherlands, and from there to India. The idea here asked more than simple browsing and tagging; it included going out into partner museums, and taking photographs of these museum collections, which were made available for a short period of time, just for the occasion. Designed as a contest among the amateurs, the project trafficked data flow between museums, Wikipedia and Flickr. These two examples show clearly that 'indirect' collaborations around an idea, contest, or a call become successful if they are based on a working community structure such as Wikipedia or Flickr.

DeviantArt has a similar, albeit smaller community, and as such, it has the same potential in assembling these types of collaborations. More important is the potential of DA in generating smallscale collaborations among its users, which is already happening without the intervention of an organisational guiding hand. If you search the DA engine for 'collaboration', more than 60.000 artworks will pop-up, which is merely the tip of the iceberg, since the DA search engine retrieves only the newest uploads.

It is quite common for a DA member (called a deviant) to put a call for collaboration, or to curate a deviation contest that invokes the idea of working together at some level. There are groups just built around the idea of collaboration for special art styles, diverging from photography or traditional visual art categories to various digital art styles or even more marginal categories such as cartoons or anime. These groups foster the spirit of sharing and creating by providing a common pool of resources, expertise, as well as by establishing a platform to publish together.

Beside these obvious undertakings, there are more fundamental working structures in DA, which emerged through the interaction and initiative of the members. I would like to mention here only the very basic ones: 'stock-images', 'resources', and 'tutorials'. All these are basically simple uploads called 'deviations', but they have an important feature in common: they are available and accessible to all deviants. DA members are allowed to generate and share these with their community (not unlike recycling ideas), as long as they are properly cited.

Stock-images are images that are freely available as building blocks for new creations. Resources are tools that are usable in specific software. For instance an artist can design a brush type for a drawing program, and make this brush available as a resource. Style sheets are another typical example for resources. Tutorials have a more special character, since their main purpose is to educate fellow members in a certain style, or a drawing program. DA offers chat-rooms, group gatherings, and e-mailing as basic web-services for its members. Through these interactive tools, users 
can make more out of such tutorials by getting help on real-time.

Obviously, DA and its digital medium offer much greater opportunities of collaborative art making than any traditional venue. In time, more elaborate web services for art creation will be designed, and the DA community will be able to collaborate in many more ways than the basic sharing and teaching activities highlighted here. For instance tools for allowing multiple users to work on the same canvas simultaneously are available, yet they are clumsy. When they are perfected, interesting experiments could be organised to take Ascott's ideas a step further: the process of creating art would not be divided any longer by the distinction of artist (the designer) versus the audience (executer), but such boundaries would become obsolete, and only the act of interaction and collaboration would remain.

\section{CONCLUSION}

The first exhibition of the Salon des Refuses received harsh critiques from the art critics of the day (Hauptmann, 1985). The artworks were either too 'hopeless' or too deviant in academic standards (Harrison, 1988, p. 510). Salon des Refuses continued to offer a home for radicals, and with time, it became a threat to the official salon and academic standards (King, 2006). Today, artists such as Manet who exhibited in Salon des Refuses are more widely known than many followers of the Academy (Bromberth, 1996).

For the 12 million members of the DeviantArt community the possibility to exhibit their art online is similar to being offered the Salon des Refuses of the $21^{\text {st }}$ century. In this modern version, (just like Wikipedia) this space becomes more than just a way to exhibit and turns into a platform with its own rules, which challenges the existing mechanisms of the current art market. As such, DA might be conceived of as a threat by its sheer existence. Simple ignorance of this community, disownment of its archive of 100 million user-generated works, rejecting even the proposition to study the dynamics of DA's structure just on the basis of its commercial background, will not render DA invisible. I suggest to analyse this online venue, not only for the sake of learning from its success in building a lively community structure, as well as for developing the potential it offers for collaborative art making, but also because it is essential to introduce a critical perspective for this new art venue, to acknowledge what is liberating in it, and to recognise the new power structures that come with it.

\section{REFERENCES}

Ascott, R. (1966) Behaviourist Art and The Cybernetic Vision. Cybernetica, Journal of the International Association for Cybernetics, 9 (4), pp. 247-264.

Ascott, R. (1968) The Cybernetic Stance: My Process And Purpose. Leonardo, 1 (2), pp, 105112.

Adamic, L.A., Lukose, R.M, Puniyani, A.R. and Huberman, B.A. (2001) Search in power-law networks. Physical review E, 64 (4), 46135.

Adams, C., Cole, T., DePaolo, C. and Edwards, S. (2001) Bringing the Curatorial Process to the Web. In Museums and the Web, 2001. http://www.archimuse.com/mw2001/papers/depaol o/depaola.html, (1 April.2010).

Becker C. and Okwui E. (1998) The Second Johannesburg Biennale. Art Journal. 57(2), pp. 86107.

Boyd, D. (2007a). Why Youth (Heart) Social Network Sites: The Role of Networked Publics in Teenage Social Life. In Buckingham D. (ed) Youth, Identity, and Digital Media, MIT Press, Cambridge, pp. 119-142.

Boyd, D. and Ellison, N. (2007b) Social network sites: Definition, history, and scholarship. Journal of Computer-Mediated Communication 13(1), article 11 ,

http://jcmc.indiana.edu/vol13/issue1/boyd.ellison.ht ml, (1 April 2010).

Brombert, B. A. (1996) Edouard Manet: Rebel in a Frock Coat. Little Brown, Boston.

Burn, I. (1975) The Art Market: Affluence and Degradation. Artforum, April, pp. 34-37.

Burn I. and Ramsden M. (2000) The Role of Language. In Harrison C., Wood P., and Gaiger J. (eds) Art in Theory, 1815-1900: An Anthology of Changing Ideas. Blackwell Pub., London, UK.

Caruth, N. and Bernstein S. (2007) Building an Online Community at the Brooklyn Museum: A Timeline. In J. Trant and D. Bearman (eds). Museums and the Web 2007: Proceedings, Toronto: Archives \& Museum Informatics, http://www.archimuse.com/mw2007/papers/caruth/ caruth.html (1 April 2010)

Clauset A., Newman M. and Moore C. (2006) Finding Community Structure In Very Large Networks. Phys. Rev., E 74, 036104. 
Gouma-Peterson, T. and Mathews P. (1987) The Feminist Critique of Art History. The Art Bulletin 69 (3), pp. 326-357.

Harrison C., Wood P., and Gaiger J. (1988) Various Authors on the Salon des Refuses 1863. In Harrison C., Wood P., and Gaiger J. (eds) Art in Theory, 1815-1900: An Anthology of Changing Ideas. Blackwell Pub, London, UK.

Hauptman, W. (1985) Juries, Protests, and Counter-Exhibitions Before 1850. The Art Bulletin, 67 (1), pp. 97-107.

Jiménez, C. (2002) The Globalization Documenta. Art Nexus. 46, pp. 64-70.

King, R. (2006) The Judgement of Paris: The Revolutionary Decade That Gave the World Impressionism. Bond Street Books, Canada.

Klein, B. (2008) The Art of Social Networking. Applied Arts. 23: 5, pp. 10-12.

Lewis K., Kaufmann J., Gonzalez M., Wimmer A., and Christakis N (2008). Tastes, Ties, and Time: A new Social Network Dataset Using Facebook.com, Social Networks, 30. pp. 330-342.

Mayer A. and Puller S.L. (2008) The Old Boy and Girl Network: Social Network Formation on University Campuses, Journal of Public Economics, 92. pp. 329-347.

Morris, J., Sharpe, E. and Stoilas, H. (2008) Exhibition attendance figures 2007. The Art Newspaper, 189, 24.
Oates, G. (2008) Many Hands Make Light Work. http://blog.flickr.net/en/2008/01/16/many-handsmake-light-work/ (1 April 2010).

O'Doherty (1999) Inside the White Cube: the ideology of the gallery space. California Uni. Pr., USA.

Preziosi D (1991) Rethinking Art History: Meditations On A Coy Science. Yale Univ Pr., USA.

Preziosi D (2003) The Brain of the Earth's Body: Art, Museums, And The Phantasms Of Modernity. Univ of Minnesota Press, USA.

Preziosi D (2009) The Art Of Art History: A Critical Anthology. Oxford University Press, USA.

Robertson I. D. (2000) Understanding International Art Markets and Management. Routledge, UK.

Russo A. and Watkins J. (2008) New Literacy New Audiences: Social Media and Cultural Institutions, EVA London 2008 Conference Proceedings.

Thelwall, M. (2009) Social network sites: Users and uses. In Marvin Zelkowitz (ed), Advances in Computers: Social Networking and the Web, 76.

Varnedoe K. and Gopnik A. (1990) High and Low: Modern Art and Popular Culture. The Museum of Modern Art, NY, USA.

Wanda C. (1988) Coming of Age: Historical Scholarship in American Art. The Art Bulletin 70 (2), pp. 189-207. 